\title{
Research into the Significance of Innovative Education Model for Cultivating Innovative Capacity in College Students
}

\author{
Feng Jiyuan \\ School of Information \& Control engineering \\ Shenyang Jianzhu University \\ Shenyang, China
}

\author{
Zhao Shengbin \\ School of Information \& Control engineering \\ Shenyang Jianzhu University \\ Shenyang, China
}

\begin{abstract}
In today's era with the development of knowledge, each country in the world is vigorously developing its economy, and without necessary innovation capacity, it is hard for a country to compete with others. Therefore, the strength of innovation capacity directly determines the strength of a country's comprehensive power. Innovation is a dominant force in national development, foster innovation in any job are essential, a person or a company's work, the work content is immutable, over time, will lose important because no features, and this is the so-called comfort lethal it, we need to continue to have input will become new elements of passion. At the request of quality education, in order to implement the strategic plan of building an innovative country, the primary task is to improve students' ability to innovate. College students to receive higher education is an important period, but also the innovative ability of the most effective period, they have a higher accumulation of knowledge than ever before and more time and effort. For schools, the need to reform the teaching mode, innovative education model to inspire students to create enthusiasm, only to achieve the purpose of this innovative education. This paper describes the importance of innovation education and through analyzing various examples of innovation education at colleges and universities, studies the purpose and requirement for cultivating innovative talents in colleges and universities, and then obtains the measures and paths to cultivate innovative talents in colleges and universities in this new era.
\end{abstract}

Keywords-Innovation, education model, innovation capacity, cultivation measures

\section{INTRODUCTION}

The present era advocates reform and promotes innovation. We want to continue to reform the system, the reform of the method so that it can more suitable for our lives; of course, we need to innovate, with new things that we can have a new life, which is the inherent requirement of socialism with Chinese characteristics. Under the Party's leadership, we continue to carry forward the spirit of the Chinese nation shouting innovation. Education is an important means to improve the level of national culture, and also improve the national innovation capability important way to occupy an important position in a country. Talent is the key to innovation is innovation implementation must have a lot of innovative talents to struggle. Education is essential to train university students' innovative ability, it saddled with higher personnel training for the country's historic mission. Requirements of education are to cultivate the spirit of innovation and creative ability of top talent. In recent years, China's ability to cultivate innovative talents of colleges and universities conducted a reform again, again and again struggled, however, on the current achievements, it is not ideal, and can not meet the country's requirements for innovation. How to promote China's development of science and technology and the economy, so that our technology and innovation in a qualitative leap is currently the major universities and the education sector should increase research efforts an important issue.

\section{CONNOTATION AND IMPORTANCE OF INNOVATION EDUCATION CONCEPT}

Innovative education is to stimulate students' creativity by nature, grant of modern scientific and cultural knowledge to inspire people inherent creative potential, develop creativity. Innovations in education are three: a pioneering teacher grant students the basics, the students has been exceeded in the wisdom of our predecessors grasp the premise, put forward his own theory perspective; mobility, with the traditional distinction of innovative education concerns more It is a new social orientation; differential, everyone is independent of the individual, in different areas have their own different ideas, should be respected and maintained.

\section{TARGETS AND REQUIREMENTS OF CULTIVATING INNOVATIVE TALENTS IN COLLEGES AND UNIVERSITIES}

Innovative talents are the country's most valuable resources, and colleges and universities as an important place for personnel training, to develop innovative education cultivating innovative talents are challenges to be faced economic times, but also the objective requirements of social development, but also the survival and development of colleges and universities must have condition. Innovative Talents for Universities mainly reflected in the sense of innovation, creativity and innovation capacity in three areas.. 


\section{A. Cultivation of Innovation Consciousness}

Consciousness is half the basis of people's willingness and good consciousness. Sense of innovation refers to a person under the stimulus certain things, have their own unique views or opinions have the desire to change the current situation. Only I had the idea and the desire to change, only to have to carry out innovative activity, so the sense of innovation is to develop students' ability to innovate important prerequisite. To cultivate awareness of innovation, first of all, have a strong curiosity, like a child, like knowledge, full of curiosity about everything, with the curious, you would be interested, curious to explore your motivation is driven; secondly, to have a strong thirst for knowledge, curiosity is a person's desire for truth and the pursuit of our daily lives, as well as a variety of life patterns of life are all common sense need to use scientific theory point of view as an explanation, then, people desire to Learn the truth, so that you can explore curiosity purposes; once again, have the necessary sense of suspicion and innovative first step is to dare to doubt the courage to question, to use a critical eye to see the problem even if the spread Millennium's point of view, the development of technology, there may no longer be correct, which need to have a sense of suspicion must, is to innovate wizard; finally, there must be a sense of quest, the quest for consciousness is that people have a kind of constant pursuit of knowledge mental state, the need to constantly update knowledge, to constantly inject fresh blood, so you need to have a strong innovative explorations of consciousness, to continue to explore and constant innovation.

\section{B. Cultivation of Innovating Thinking}

Innovative thinking refers to a series of activities during the innovation process of thinking human can generate thinking activities unique, innovative insights, as a core part of the innovative ability and quality of students in colleges and universities in the dominant culture. When there was a sense of innovation, the need for a series of innovative activities and innovative thinking needs throughout the innovation activities. There are also several specific innovative thinking, divergent thinking, given a topic, a point of view, to be able to be considered from many aspects, it extends from the center out, not to be bound by traditional ideas, an open mind. Its requirement is to have a profound cultural foundation, so that it can be analyzed differently from different disciplines, different areas, different reason for the same problem, so as to achieve the purpose of innovation; convergent thinking, divergent thinking and corresponding The method itself of knowledge fusion, close to the center of the problem from all angles, in order to find the best solution, this method requires that the powerful logic capacity; in addition, there is the image of thinking, by image or imagination to make a figurative mode of thinking of things, which is characterized by clear and unambiguous able to describe things.

\section{Cultivation of Innovation Capacity}

Innovation capability is a potential, is carrying out innovative activity has shown a potential, only draper students the ability to create, to make it more able to use a variety of creative work, according to the new era, new educational model for Training creative ability in college, you can include the following: good observation skills, be good to observe all kinds of things, be able to notice the subtle changes, to discover the characteristics of each thing; the ability to organize learning activities, innovative education model requires students to be self-learning, you can group together to discuss, research, combined with our common idea, the idea put forward could be more perfect; ability to analyze problems, problems to learn to analyze, analyze the relationship between the various parts, and thus find the key point; ability to express their own ideas, to be able to complete a clear statement out, so that the audience can understand, otherwise, only you know, nobody can help identify the problem analysis, the innovation process will be very difficult.

\section{RESEARCHES INTO PROBLEMS OF CULTIVATING INNOVATIVE TALENTS IN CHINA'S COLLEGES AND UNIVERSITIES AT PRESENT}

\section{A. Hysteretic Concept and Insufficient Consciousness}

The traditional educational philosophy is deeply rooted in our country, its heritage advocates ancestors wisdom to students to establish a kind of knowledge is handed down for thousands of years, it is the result of numerous scientifically validated, is sacrosanct indisputable image. But with the development of the times, the traditional theory may no longer adapt to the development of modern society, at the same time, the development of technology may also be detected before the theory that we can not find a vulnerability, so first of all, dared to question, dare to challenge the authority is innovative the first step, but the traditional concepts of education seriously hindered the development of innovation. The teacher has been implemented according to the traditional education students but speak just listen to this teaching model, to stimulate students' creative thinking for the formation of the sense of innovation is not any help.

\section{B. Obsolete Contents and Single and Backward Means}

Innovative education requires knowledge of the system is to carry out scientific finishing, forming an innovative curriculum. For most universities, but now all have their name, not in fact. We are now in the information age, a huge amount of information that requires us to have a strong ability to collect and use the information, which has been the soft underbelly of the major colleges and universities. The most important set of teaching contents and curriculum have been out of touch with the times, we have been unable to meet the development needs of the community now. Practice teaching is to complement and strengthen the theory teaching, but also innovation requires education. However, most universities often because of financial problems and lack of practice teaching, the students do not get enough opportunities for hands-on practice. For innovative teaching, the theory and practice are indispensable, but neglected to practice teaching universities hindered the development and progress of innovative education from an objective, ultimately leading to students' innovation capability is weak, can not meet the needs of the community. 


\section{Obstacles in Evaluating Traditional Teaching}

With the development of quality education, the traditional assessment system has been unable to adapt to the requirements of innovation and education, but at present, most universities still practice teaching mode of examination-oriented education, test scores, although there is some assessment of student learning outcomes, but also devoid of the ability of students to think independently, to form a score is the only standard measure of ideas student learning outcomes. Only to test scores to evaluate the overall quality of students is obviously not desirable, it must change education model, changing concepts of education.

\section{Lack of Scientific Teaching Management System and Political Support}

Traditional teaching overemphasis unified management system and norms, to cultivate students' creative ability, the lack of the necessary flexibility and adaptability. Teaching management and teaching plans realistic lines, test management and teaching evaluation system and so on cannot provide strong support for innovative education. Creative Education arduous tasks, schools and individual students alone are not enough, the state government policy also need to provide the necessary support. But although the university to do a variety of innovative education in promoting a variety of encouragement, but it is still among the teachers and students in a dispensable position, the teacher students do not have the appropriate incentives, lack of motivation, innovation and education is only one final species floating on the surface and formality of oral education.

\section{MEASURES AND PATHS ON CULTIVATING INNOVATIVE TALENTS IN COLLEGES IN THE NEW ERA}

\section{A. Innovation of Education Concept}

Innovative education advocates individuality, to cultivate students' creative ability should first establish a sense of innovation, understanding of the importance of innovation. To establish the education of democratic, open, change, and establish the right knowledge and talent. First, update the ideas, cultivate innovative talents instantly enhance national innovation, and is closely related to the nation's rise and fall, in order to provide effective protection for educational reform. With innovative ideas will inspire desire innovative, policy-makers should be guided in the right direction for the innovative education, to ensure good health and development of the education system

\section{B. Cultivation of Innovative Mode}

Innovative training model uses training model, so that people can positively think about and seriously discuss problems when they meet with problems. Change the traditional teaching methods to improve students' interest, freed them from boring classroom. With the reform of the education system change, the focus of education, traditional teaching methods can not meet the needs of the present stage of classroom education. After should mobilize the enthusiasm of the students, the teachers will teach students the basics, we should pay attention to the guide, let students divergent thinking, cooperation and explore issues. Encourage the same problem from different directions to analyze students' multi-angle look at the issue of capacity. In addition, one should teach students selfexploration, innovation awareness, teacher, and are not necessarily on the textbook, and their own daring to question the pursuit of seeking truth from facts, encounter problems, and ask questions, common solutions.

\section{Innovation of Teaching Means}

The reform of teaching methods is an important way to promote innovation and education, is the inevitable choice of the times. Traditional teaching and development of colleges and universities now can not adapt, we urgently need to introduce a set of new teaching methods. Meanwhile, increase the efforts in the application of multimedia tools to give students a better understanding with vivid pictures or videos. The most important laboratory establish imminent, without practice is empty theory, practice is to create the beginning of thinking.

\section{CONCLUSION}

All in all, nowadays, innovation is an important factor influencing the development of a country as well as the deciding factor of comprehensive national strength. The progress of a nation needs the contributions of innovative talents. Colleges and universities are important cradle of a country to cultivate high-quality talents, so we must vigorously develop innovation education in a bid to constantly cultivate students' innovation capacity.

\section{REFERENCES}

[1] Li Caijun. Exploration of Cultivating College Students' Innovation Capacity [M]. Chongqing: Chongqing Press, 2006.

[2] Zhao Qingmin. Cultivation of Innovation Capacity [M]. Wuhan: Huazhong University of Science and Technology Press, 2002.

[3] Li Shihai, Gao Zhaohong, Zhang Xiaoyi. Exploration of Innovation Education [M]. Beijing: Social Science Literature Press, 2005.

[4] Zhao Jiayi, Creative Education Outline [M]. Chengdu: Sichuan Education Press, 2005.

[5] Hao Keming. Cultivating Top-Notch Innovative Talents and Reform and Higher Education [J]. Research into Higher Education in China, 2003 (11) : 7-12.

[6] Zhang Xiuping. Cultivating Top-Notch Innovative Talents and Innovating College Education [J]. Journal of Dalian University of Technology (social science edition), 2005 (3) : 9-15.

[7] Wei Qiaoyan. Discussion into Models to Cultivate Talents in Colleges [J]. Reform and Strategies, 2007, (11).

[8] Ying Jie, Liu Baocun. Innovative Education at Colleges from International Prospect [M]. Taiyuan: Shanxi Education Press, 2005.10-13.

[9] Wang Fei. Discussion of Studios of Cultivating Innovative Talents in Reality [J] Journal of Jiangsu College of Engineering and Technology (comprehensive edition), 2011, 11 (1) : 85-88.

[10] Li Lin. "Review and Prospect of Quality Education in Chinese Universities", "Research into Education at Tsinghua University", the 3rd edition in 2000.

[11] Han Jianhua, Chen Xin. On Exam Reform at Colleges and Cultivating Innovative Talents [J] Journal of Nanchang Teachers College, 2007, 73(6):60-62. 